\section{(6) OPEN ACCESS}

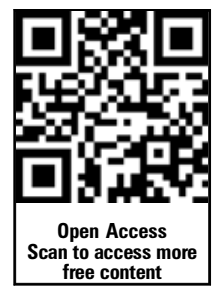

- Additional material is published online only. To view please visit the journal online (http://dx.doi.org/10.1136/ heartjnl-2013-303678).

${ }^{1} \mathrm{MRC}$ Centre for Causal Analyses in Translational Epidemiology, School of Social and Community Medicine, University of Bristol, Bristol, UK ${ }^{2}$ Norwich Medical School, University of East Anglia, Norwich, UK ${ }^{3}$ Centre for Paediatric Epidemiology and Biostatistics, and Medical Research Council Centre of Epidemiology for Child Health, University College London Institute of Child Health, London, UK ${ }^{4}$ Institute of Child Health, University College London, London, UK

${ }^{5}$ Genetic Epidemiology Group, Department of Epidemiology and Public Health, University College London, London, UK ${ }^{6}$ BHF Glasgow Cardiovascular Research Centre, University of Glasgow, Glasgow, UK

\section{Correspondence to} Professor Debbie Lawlor, School of Social and Community Medicine University of Bristol, Oakfield House, Oakfield Grove, Bristol BS8 2BN, UK; d.a.lawlor@bristol.ac.uk

Received 21 January 2013 Revised 31 July 2013 Accepted 3 August 2013 Published Online First 14 October 2013

\title{
Associations of maternal 25-hydroxyvitamin $D$ in pregnancy with offspring cardiovascular risk factors in childhood and adolescence: findings from the Avon Longitudinal Study of Parents and Children
}

\author{
Dylan M Williams, ${ }^{1}$ Abigail Fraser, ${ }^{1}$ William D Fraser, ${ }^{2}$ Elina Hyppönen, ${ }^{3}$ \\ George Davey Smith, ${ }^{1}$ John Deanfield, ${ }^{4}$ Aroon Hingorani, ${ }^{5}$ Naveed Sattar, ${ }^{6}$ \\ Debbie A Lawlor ${ }^{1}$
}

\begin{abstract}
Objective Lower maternal vitamin D status in pregnancy may be associated with increased offspring cardiovascular risk in later life, but evidence for this is scant. We examined associations of maternal total 25-hydroxyvitamin $D(25(\mathrm{OH}) \mathrm{D})$ in pregnancy with offspring cardiovascular risk factors assessed in childhood and adolescence.
\end{abstract}

Design A longitudinal, prospective study. Setting The study was based on data from motheroffspring pairs in the Avon Longitudinal Study of Parents and Children (ALSPAC), a UK prospective populationbased birth cohort ( $\mathrm{N}=4109$ ).

Outcome measures Offspring cardiovascular risk factors were measured in childhood (mean age 9.9 years) and in adolescence (mean age 15.4 years): blood pressure, lipids, apolipoproteins (at 9.9 years only), glucose and insulin (at 15.4 years only), C reactive protein (CRP), and interleukin 6 (at 9.9 years only) were measured.

Results After adjustments for potential confounders (maternal age, education, body mass index (BMI), smoking, physical activity, parity, socioeconomic position, ethnicity, and offspring gestational age at 25(OH)D sampling; gender, age, and BMI at outcome assessment), maternal 25(OH)D was inversely associated with systolic blood pressure $(-0.48 \mathrm{~mm} \mathrm{Hg}$ difference per $50 \mathrm{nmol} / \mathrm{L}$ increase in $25(\mathrm{OH}) \mathrm{D} ; 95 \% \mathrm{Cl}-0.95$ to $-0.01)$, Apo-B $(-0.01 \mathrm{mg} / \mathrm{dL}$ difference; $95 \% \mathrm{Cl}-0.02$ to -0.001 ), and CRP ( $-6.1 \%$ difference; $95 \% \mathrm{Cl}$ $-11.5 \%$ to $-0.3 \%$ ) at age 9.9 years. These associations were not present for risk factors measured at 15.4 years, with the exception of a weak inverse association with CRP (-5.5\% difference; $95 \% \mathrm{Cl}-11.4 \%$ to $0.8 \%$ ). There was no strong evidence of associations with offspring triglycerides, glucose or insulin.

Conclusions Our findings suggest that fetal exposure to $25(\mathrm{OH}) \mathrm{D}$ is unlikely to influence cardiovascular risk factors of individuals later in life.

\section{INTRODUCTION}

Low vitamin D status, assessed by circulating total 25 -hydroxyvitamin $\mathrm{D}(25(\mathrm{OH}) \mathrm{D})$, is common in pregnancy. ${ }^{1}{ }^{2}$ Maternal 25(OH)D diffuses freely across the placenta, and fetal exposure to vitamin $\mathrm{D}$ depends solely on concentrations in the mother. ${ }^{3}$
There is increasing evidence that vitamin D status in pregnancy may influence normal fetal growth and development, and influence offspring health outcomes in later life. Recent observational studies have reported associations of low maternal $25(\mathrm{OH}) \mathrm{D}$ concentrations or dietary vitamin $\mathrm{D}$ intake with lower bone mineral accrual, ${ }^{45}$ and increased risk of type 1 diabetes $^{6}$ and wheezing ${ }^{7}$ in offspring. It has also been suggested that lower concentrations of maternal $25(\mathrm{OH}) \mathrm{D}$ in pregnancy might be related to increased risk of insulin resistance (measured by the homeostasis model of assessment-insulin resistance; HOMA-IR), and hence cardiovascular disease, in offspring in later life. ${ }^{8}$

There are several plausible pathways by which maternal $25(\mathrm{OH}) \mathrm{D}$ in pregnancy may relate to future cardiovascular health of offspring. First, some, ${ }^{9-11}$ though not all, ${ }^{12}{ }^{13}$ studies have shown an association of lower $25(\mathrm{OH}) \mathrm{D}$ concentration in pregnancy with maternal risk of pre-eclampsia and with low birth weight/risk of a small for gestational age birth in their infants, and these have been associated with future cardiovascular risk in offspring. ${ }^{14-16}$ Secondly, a number of studies have reported associations of lower circulating $25(\mathrm{OH}) \mathrm{D}$ with adverse cardiovascular risk factors in children, adolescents, and adults. ${ }^{17}{ }^{18}$ It is therefore possible that maternal 25 $(\mathrm{OH}) \mathrm{D}$ in pregnancy will be associated with offspring cardiovascular risk factors because maternal and offspring $25(\mathrm{OH}) \mathrm{D}$ are correlated due to shared environmental and genetic determinants of $25(\mathrm{OH}) \mathrm{D}$ (ie, maternal $25(\mathrm{OH}) \mathrm{D}$ in pregnancy will relate to offspring outcomes at least in part because it reflects the child's own concentrations). Thirdly, it is possible that variation in exposure to intrauterine concentrations of $25(\mathrm{OH}) \mathrm{D}$ programmes fetal development and influences arterial structure and metabolic processes that affect future cardiovascular health. However, only two small studies have examined associations of maternal $25(\mathrm{OH}) \mathrm{D}$ concentrations during pregnancy and cardiovascular disease risk factors of offspring to date. ${ }^{819}$ The small sample sizes of both of these studies (with 178 and 539 maternaloffspring pairs) could have limited their ability to detect associations.

Our aim was to examine associations of maternal $25(\mathrm{OH}) \mathrm{D}$ concentrations measured in pregnancy 
with a range of offspring cardiovascular risk factors (blood pressure, lipids, apolipoproteins (Apo-A1, Apo-B), fasting glucose and insulin, $\mathrm{C}$ reactive protein (CRP), and interleukin 6 (IL6)) measured during childhood (mean age 9.9 years) and again in adolescence (mean age 15.4 years).

\section{METHODS}

\section{Participants}

The Avon Longitudinal Study of Parents and Children (ALSPAC) is a prospective birth cohort that recruited pregnant women $(\mathrm{N}=14541)$ living within the former county of Avon, South West England. Women with an expected delivery date between 1 April 1991 and 31 December 1992 were eligible to be included. Study details have been published, ${ }^{20} 21$ and are found online at http://www.bristol.ac.uk/alspac/. A total of 13988 live born children who survived past age 1 year have been followed up alongside their mothers with questionnaires during early childhood, and at regular assessments from age 7. Ethical approval was granted by the ALSPAC Law and Ethics Committee and the local research ethics committee. Written informed consent/assent was obtained from both parents/guardians and the children. For this study, we used measures of $25(\mathrm{OH}) \mathrm{D}$ concentrations from blood samples collected from mothers during pregnancy as part of their routine follow-up, and offspring cardiovascular risk factors measured when the offspring attended the year 9.9 and 15.4 year follow-up assessments. Our eligible sample consists of 4109 maternal-offspring pairs with a maternal $25(\mathrm{OH}) \mathrm{D}$ measure from pregnancy and offspring cardiovascular risk factors measured at mean age 9.9 or 15.4 years (see figure 1 ).

\section{Measures}

Details of $25(\mathrm{OH}) \mathrm{D}$ assaying, and measurements of outcomes and co-variables, are included in the online supplementary material.

\section{Statistical analysis}

A large proportion of our sample $(\mathrm{N}=3169$; 77.1\%) had maternal $25(\mathrm{OH}) \mathrm{D}_{2}$ concentrations at or below the assay detection limit $(1.25 \mathrm{nmol} / \mathrm{L})$. These were assigned a value of $0 \mathrm{nmol} / \mathrm{L}$. A measure of total $25(\mathrm{OH}) \mathrm{D}$ was then calculated from the sum of $25(\mathrm{OH}) \mathrm{D}_{2}$ and $25(\mathrm{OH}) \mathrm{D}_{3}$ and all associations are of maternal total $25(\mathrm{OH}) \mathrm{D}$ with offspring outcomes. $25(\mathrm{OH}) \mathrm{D}$ was adjusted for season of sampling, as previously described. ${ }^{18}$ Briefly, 25(OH)D was modelled against the date of blood sampling using linear regression with trigonometric sine and cosine functions, and residuals of regression models were used as season-adjusted $25(\mathrm{OH}) \mathrm{D}$ in main analyses.

To test the strength of linear associations between the 25 $(\mathrm{OH}) \mathrm{D}$ measures (unadjusted and season-adjusted maternal 25 $(\mathrm{OH}) \mathrm{D}$, and unadjusted and season-adjusted offspring 25 $(\mathrm{OH}) \mathrm{D})$, we calculated Pearson correlation coefficients for pairs of measures.

Multivariable linear regression models were used to examine associations of maternal $25(\mathrm{OH}) \mathrm{D}$ with cardiovascular risk factors, and to adjust for potential confounding and mediating factors. Regression coefficients and 95\% CI were formatted to show mean differences in outcomes per $50 \mathrm{nmol} / \mathrm{L}$ increase in $25(\mathrm{OH}) \mathrm{D}$. Coefficients for log-transformed outcomes (triglycerides, insulin, CRP, and IL6) were expressed in terms of relative percent change per $50 \mathrm{nmol} / \mathrm{L}$ increase in $25(\mathrm{OH}) \mathrm{D}$, by reformatting ratios of geometric means and $95 \%$ CIs.

We conducted several multivariable linear regression models for each exposure-outcome association. In model 1, associations were adjusted for maternal age at delivery, offspring gender, gestational age at $25(\mathrm{OH}) \mathrm{D}$ sampling, age at the year 9.9 or 15.4 assessments, parity, maternal education, household socioeconomic position, ethnicity, maternal pre-pregnancy body mass index (BMI), smoking and physical activity in pregnancy, and offspring BMI at the year 9.9 or 15.4 assessment. We included adjustment for offspring BMI because maternal $25(\mathrm{OH}) \mathrm{D}$ is inversely associated with maternal BMI, a mother's BMI may relate to her child's BMI, and offspring BMI is associated with their cardiovascular risk factors. As such, offspring BMI could lie on the confounding pathway. In model 2 , we additionally adjusted for potential mediation of associations by offspring 25(OH)D measured in childhood. Model 3 included adjustments for confounders as in model 2, and additional adjustments for potential mediation by gestational hypertension, pre-eclampsia, gestational diabetes mellitus or glycosuria during pregnancy, and birth weight. Possible non-linearity of associations between exposures and outcomes was tested by examining fractional polynomial statistics and interpreting graphical plots. $^{22}$

In addition to examining linear associations, we also conducted multivariable regression analyses examining mean differences of cardiovascular risk factors in offspring with maternal $25(\mathrm{OH}) \mathrm{D}<50 \mathrm{nmol} / \mathrm{L}$ and in offspring with maternal 25 $(\mathrm{OH}) \mathrm{D}$ between $50-75 \mathrm{nmol} / \mathrm{L}$, compared to risk factors in offspring with maternal $25(\mathrm{OH}) \mathrm{D}>75 \mathrm{nmol} / \mathrm{L}^{2}$

\section{Missing data}

There were proportions of our eligible sample who had missing data on one or more variable used to examine associations with cardiovascular risk factors at 9.9 years $(\mathrm{N}=2010 ; 48.9 \%)$ and 15.4 years $(\mathrm{N}=2807 ; 68.3 \%)$. To address this, we used multivariate multiple imputation to impute missing information on outcomes and covariables for otherwise eligible maternal-offspring pairs with valid maternal $25(\mathrm{OH}) \mathrm{D}$ measures from pregnancy and who had attended the year 9.9 or 15.4 assessments. This approach involves switching regression, using the multivariate imputation by chained equations function in Stata. ${ }^{23}$ Twenty cycles of regression switching were used, and estimates of results were averaged across the 20 imputed datasets according to Rubin's rules. ${ }^{23}$ Main analyses were conducted using these datasets.

\section{Additional analyses}

We repeated main analyses using maternal 25(OH)D unadjusted for season of sampling as an exposure. We also repeated main analyses excluding participants whose CRP values suggested acute inflammation (CRP $>6 \mathrm{mg} / \mathrm{L}$ ).

We tested associations for interactions between maternal $25(\mathrm{OH}) \mathrm{D}$ concentrations and trimester of sampling, and examined results after stratifying by trimester.

We also conducted analyses in the subsamples of participants with complete information on maternal $25(\mathrm{OH}) \mathrm{D}$, co-variables and offspring cardiovascular risk factors at mean age 9.9 years $(\mathrm{N}=2099)$ and 15.4 years $(\mathrm{N}=1302)$.

Given that non-high density lipoprotein cholesterol (non-HDL-C: total cholesterol minus HDL-C) has been implicated as being more strongly associated with cardiovascular events than separate lipid components alone, ${ }^{24}$ we also repeated analyses including non-HDL-C as an outcome. Since a previous study has reported an inverse association of maternal $25(\mathrm{OH}) \mathrm{D}$ in pregnancy with offspring insulin resistance as measured by HOMA-IR, ${ }^{8}$ we also repeated analyses with this measure as an outcome, calculated using the standard formula. ${ }^{25}$ 


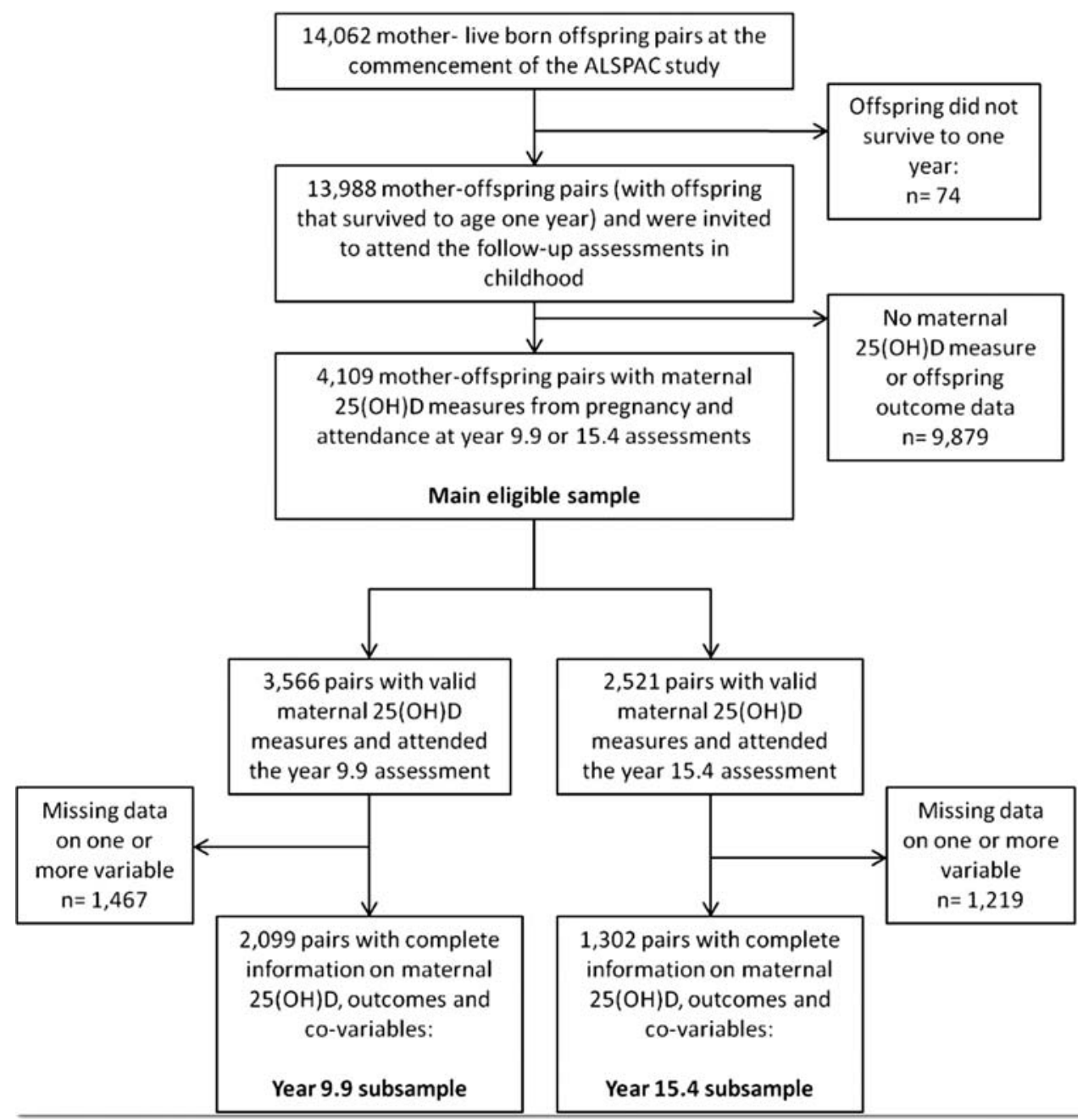

Figure 1 Flow chart of study participants. 25(OH)D, 25-hydroxyvitamin D; ALSPAC, Avon Longitudinal Study of Parents and Children.

\section{RESULTS}

Characteristics of ALSPAC mothers and offspring in the eligible sample, along with characteristics of those who were excluded because of missing data, are shown in online supplemental tables S1 and S2.

Table 1 shows characteristics of ALSPAC mothers and offspring according to categories of maternal $25(\mathrm{OH}) \mathrm{D}$ in pregnancy. Maternal age at 25(OH)D sampling in pregnancy, socioeconomic position, maternal education, physical activity, percentage who had never smoked during pregnancy, gestational age at $25(\mathrm{OH}) \mathrm{D}$ sampling, birth weight, and offspring $25(\mathrm{OH}) \mathrm{D}$ all increased linearly from lower to higher maternal $25(\mathrm{OH}) \mathrm{D}$ categories. Parity, percentage of non-white European ethnicity, and percentage who smoked throughout pregnancy all decreased across categories of maternal $25(\mathrm{OH}) \mathrm{D}$. Of risk factors measured at mean age 9.9 years, HDL-C and Apo-A1 increased across low to high categories of maternal $25(\mathrm{OH}) \mathrm{D}$, while diastolic blood pressure (DBP), low density lipoprotein cholesterol (LDL-C) and Apo-B decreased across the categories. Similar trends were observed for LDL-C, HDL-C, and CRP measured at mean age 15.4 years. No trends with other risk factors were observed.

Online supplemental table $\mathrm{S} 3$ shows correlations of unadjusted and season-adjusted maternal 25(OH)D, and also offspring unadjusted and season-adjusted $25(\mathrm{OH}) \mathrm{D}$ sampled at mean age 9.8 years. There were weak positive correlations of unadjusted and season-adjusted maternal $25(\mathrm{OH}) \mathrm{D}$ with unadjusted and season-adjusted offspring 25(OH)D (all Pearson's $\mathrm{r}=0.11$ to 0.15 ; all $\mathrm{p}<0.001$ ).

Table 2 shows multivariable associations of maternal $25(\mathrm{OH}) \mathrm{D}$ with offspring cardiovascular risk factors. In model 1, there were inverse associations of maternal $25(\mathrm{OH}) \mathrm{D}$ with systolic blood pressure (SBP), Apo-B and CRP, and weak inverse associations with DBP and IL6, at mean age 9.9 years. At mean age 15.4 years there were no associations with SBP or DBP, but a weak inverse association with CRP was present. Further adjustments for offspring $25(\mathrm{OH}) \mathrm{D}$ (model 2) and other potential mediators (model 3) did not substantially change results observed in model 1, although the association of $25(\mathrm{OH}) \mathrm{D}$ with CRP at 9.9 years attenuated slightly in model 2. Figure 2 shows the confounder-adjusted associations with risk factors that were measured at both ages, with all results on a scale of percentage difference per $50 \mathrm{nmol} / \mathrm{L}$ increase in $25(\mathrm{OH}) \mathrm{D}$. It can be seen that the directions and magnitudes of associations with CRP are similar at both age points.

Online supplemental table S4 shows mean differences in cardiovascular risk factors in offspring whose mothers had $25(\mathrm{OH}) \mathrm{D}$ from $50-75 \mathrm{nmol} / \mathrm{L}$ or $25(\mathrm{OH}) \mathrm{D}<50 \mathrm{nmol} / \mathrm{L}$ in pregnancy, compared to those whose mothers had $25(\mathrm{OH}) \mathrm{D}>75 \mathrm{nmol} / \mathrm{L}$. On average, Apo-B at 9.9 years was higher in offspring with maternal $25(\mathrm{OH}) \mathrm{D}$ concentrations $<50 \mathrm{nmol} / \mathrm{L}$ or $50-75 \mathrm{nmol} / \mathrm{L}$ compared 
Table 1 Characteristics of ALSPAC mothers and offspring by categories of maternal 25(OH)D concentration pregnancy (\% or mean and $95 \% \mathrm{Cl}$; the column marked ' $\mathrm{N}$ ' denotes the number of participants in the analysis sample with available data for each variable)

\begin{tabular}{|c|c|c|c|c|c|c|c|c|c|c|}
\hline \multirow{2}{*}{ Maternal characteristics } & \multirow[t]{2}{*}{$\mathbf{N}$} & \multicolumn{2}{|c|}{$25(\mathrm{OH}) \mathrm{D}<25 \mathrm{nmol} / \mathrm{L}$} & \multicolumn{2}{|l|}{$\begin{array}{l}25(\mathrm{OH}) \\
\mathrm{D}=25-49\end{array}$} & \multicolumn{2}{|c|}{$25(\mathrm{OH}) \mathrm{D}=50-75 \mathrm{nmol} / \mathrm{L}$} & \multicolumn{2}{|c|}{$25(\mathrm{OH}) \mathrm{D}>75 \mathrm{nmol} / \mathrm{L}$} & \multirow[t]{2}{*}{$\mathrm{p}$ Value } \\
\hline & & & & & & & & & & \\
\hline Maternal age at delivery & 4031 & 27.5 & (26.7 to 28.2 ) & 28.6 & (28.3 to 28.8 ) & 28.8 & (28.6 to 29.1 ) & 29.4 & (29.2 to 29.6 ) & $<0.001$ \\
\hline$\%$ Parity & 4109 & & & & & & & & & \\
\hline 0 & & 55.8 & & 47.0 & & 45.9 & & 42.1 & & 0.001 \\
\hline 1 & & 32.7 & & 34.4 & & 34.2 & & 38.4 & & 0.02 \\
\hline 2 & & 9.5 & & 13.3 & & 15.0 & & 14.4 & & 0.15 \\
\hline 3 & & 2.0 & & 3.2 & & 4.0 & & 4.5 & & 0.05 \\
\hline 4 or 5 & & 0.0 & & 2.0 & & 0.9 & & 0.6 & & 0.02 \\
\hline$\%$ Non-white European ethnicity & 4109 & 8.5 & & 2.5 & & 1.2 & & 0.9 & & $<0.001$ \\
\hline$\%$ Socioeconomic position & 4109 & & & & & & & & & \\
\hline $\mathrm{I} / \mathrm{I}$ & & 51.9 & & 56.3 & & 59.6 & & 61.7 & & $<0.001$ \\
\hline III (non-manual) & & 28.2 & & 26.2 & & 25.7 & & 24.0 & & 0.35 \\
\hline III (manual) & & 14.8 & & 12.8 & & 10.6 & & 10.7 & & 0.10 \\
\hline IV/V & & 5.2 & & 4.8 & & 4.2 & & 3.7 & & 0.22 \\
\hline Maternal education (\% attended university) & 3868 & 12.1 & & 14.9 & & 15.1 & & 16.7 & & 0.09 \\
\hline Pre-pregnancy BMI & 3620 & 22.7 & (22.1 to 23.3 ) & 22.9 & (22.7 to 23.1 ) & 22.9 & (22.7 to 23.1 ) & 22.7 & (22.5 to 22.9 ) & 0.20 \\
\hline Maternal smoking (\%) & 4109 & & & & & & & & & \\
\hline Never & & 72.5 & & 75.0 & & 80.7 & & 83.4 & & $<0.001$ \\
\hline Before or during first trimester & & 4.0 & & 6.7 & & 5.7 & & 5.4 & & 0.44 \\
\hline Throughout pregnancy & & 23.5 & & 18.3 & & 13.6 & & 11.3 & & $<0.001$ \\
\hline Maternal physical activity in pregnancy (MET)* & 3268 & 9.9 & (8.2 to 12.0$)$ & 11.3 & (10.5 to 12.1$)$ & 12.0 & (11.2 to 12.8$)$ & 12.6 & (11.9 to 13.4$)$ & 0.003 \\
\hline$\%$ Gestational hypertension & 3947 & 15.5 & & 14.4 & & 15.3 & & 13.0 & & 0.23 \\
\hline$\%$ Pre-eclampsia & 4013 & 2.6 & & 1.8 & & 1.4 & & 1.6 & & 0.42 \\
\hline$\%$ Gestational diabetes & 3951 & 0.0 & & 0.7 & & 0.8 & & 0.5 & & 0.98 \\
\hline$\%$ Glycosuria in pregnancy & 4109 & 2.5 & & 3.2 & & 2.8 & & 2.4 & & 0.31 \\
\hline \multicolumn{11}{|l|}{ Offspring characteristics } \\
\hline$\%$ male & 4109 & 54.4 & & 49.5 & & 51.9 & & 52.2 & & 0.39 \\
\hline Gestational age at $25(\mathrm{OH}) \mathrm{D}$ sampling (weeks) & 4109 & 24.0 & (22.3 to 25.7$)$ & 23.4 & (22.8 to 24.0$)$ & 23.7 & (23.1 to 24.3 ) & 25.7 & (25.1 to 26.2 ) & $<0.001$ \\
\hline Birth weight $(\mathrm{kg})$ & 3982 & 3.3 & (3.2 to 3.4 ) & 3.4 & (3.4 to 3.5 ) & 3.4 & (3.4 to 3.5 ) & 3.5 & (3.5 to 3.5$)$ & $<0.001$ \\
\hline Age at year 9.9 assessment (years) & 3566 & 9.94 & (9.89 to 10.00$)$ & 9.87 & (9.85 to 9.89$)$ & 9.84 & (9.82 to 9.86 ) & 9.86 & (9.85 to 9.88$)$ & 0.16 \\
\hline Age at year 15.4 assessment (years) & 2521 & 15.51 & (15.44 to 15.57$)$ & 15.45 & (15.42 to 15.47$)$ & 15.44 & (15.42 to 15.46$)$ & 15.44 & (15.42 to 15.46$)$ & 0.21 \\
\hline BMI at year 9.9 assessment $(\mathrm{kg} / \mathrm{m} 2)$ & 3525 & 17.6 & (17.1 to 18.0$)$ & 17.7 & (17.5 to 17.8$)$ & 17.6 & (17.4 to 17.8$)$ & 17.7 & (17.5 to 17.8$)$ & 0.87 \\
\hline BMI at year 15.4 assessment $(\mathrm{kg} / \mathrm{m} 2)$ & 2497 & 21.4 & (20.7 to 22.1 ) & 21.3 & (21.1 to 21.6 ) & 21.3 & (21.1 to 21.6 ) & 21.2 & (20.9 to 21.4 ) & 0.27 \\
\hline Childhood 25(OH)D (nmol/L) & 4099 & 22.9 & (21.4 to 24.3 ) & 24.4 & (23.8 to 24.9 ) & 25.3 & (24.8 to 25.9 ) & 26.6 & (26.1 to 27.0 ) & $<0.001$ \\
\hline \multicolumn{11}{|l|}{ Year 9.9 risk factors } \\
\hline $\mathrm{SBP}(\mathrm{mm} \mathrm{Hg})$ & 3525 & 102.9 & (101.4 to 104.5$)$ & 102.9 & (102.3 to 103.5 ) & 102.5 & (101.9 to 103.0 ) & 102.3 & (101.8 to 102.8 ) & 0.10 \\
\hline $\mathrm{DBP}(\mathrm{mm} \mathrm{Hg})$ & 3527 & 57.6 & (56.5 to 58.7 ) & 57.7 & (57.3 to 58.1 ) & 57.3 & (56.9 to 57.6 ) & 57.2 & (56.8 to 57.5 ) & 0.05 \\
\hline Triglycerides $(\mathrm{mmol} / \mathrm{L}) \dagger$ & 2770 & 0.99 & (0.91 to 1.08) & 1.05 & (1.02 to 1.08$)$ & 1.03 & (1.00 to 1.06$)$ & 1.03 & (1.00 to 1.06$)$ & 0.80 \\
\hline LDL-C (mmol/L) & 2770 & 2.39 & (2.28 to 2.51 ) & 2.37 & (2.32 to 2.41$)$ & 2.32 & (2.28 to 2.36 ) & 2.31 & (2.28 to 2.35 ) & 0.05 \\
\hline $\mathrm{HDL}-\mathrm{C}(\mathrm{mmol} / \mathrm{L})$ & 2770 & 1.38 & (1.32 to 1.44$)$ & 1.38 & (1.36 to 1.40$)$ & 1.41 & (1.39 to 1.43 ) & 1.41 & (1.39 to 1.43 ) & 0.02 \\
\hline Apo-A1 (mg/dL) & 2770 & 1.33 & (1.29 to 1.37$)$ & 1.35 & (1.34 to 1.37$)$ & 1.37 & (1.35 to 1.38 ) & 1.37 & (1.35 to 1.38$)$ & 0.04 \\
\hline Apo-B (mg/dL) & 2770 & 0.61 & (0.58 to 0.63$)$ & 0.60 & (0.59 to 0.61$)$ & 0.59 & (0.58 to 0.59 ) & 0.58 & (0.57 to 0.59 ) & 0.002 \\
\hline $\mathrm{CRP}(\mathrm{mg} / \mathrm{L}) \dagger$ & 2388 & 0.26 & (0.21 to 0.33$)$ & 0.29 & (0.27 to 0.31$)$ & 0.26 & (0.24 to 0.28$)$ & 0.26 & (0.24 to 0.28$)$ & 0.10 \\
\hline IL6 (pg/mL)† & 2760 & 0.86 & (0.73 to 1.01$)$ & 0.88 & (0.83 to 0.94 ) & 0.83 & (0.78 to 0.88 ) & 0.82 & (0.78 to 0.87 ) & 0.12 \\
\hline \multicolumn{11}{|l|}{ Year 15.4 risk factors } \\
\hline $\mathrm{SBP}(\mathrm{mm} \mathrm{Hg})$ & 2388 & 122.6 & (120.3 to 125.0$)$ & 122.7 & (121.8 to 123.5$)$ & 122.7 & (122.0 to 123.5 ) & 123.5 & (122.7 to 124.2 ) & 0.15 \\
\hline $\mathrm{DBP}(\mathrm{mm} \mathrm{Hg})$ & 2388 & 67.5 & (65.7 to 69.4$)$ & 67.5 & (66.8 to 68.1$)$ & 67.2 & (66.6 to 67.8 ) & 67.7 & (67.2 to 68.3 ) & 0.55 \\
\hline Triglycerides $(\mathrm{mmol} / \mathrm{L}) \dagger$ & 1760 & 0.77 & (0.71 to 0.85 ) & 0.77 & (0.75 to 0.80$)$ & 0.77 & (0.75 to 0.79 ) & 0.76 & (0.74 to 0.78 ) & 0.33 \\
\hline LDL-C (mmol/L) & 1760 & 2.16 & (2.02 to 2.29 ) & 2.11 & (2.06 to 2.16 ) & 2.08 & (2.03 to 2.12 ) & 2.07 & (2.02 to 2.11 ) & 0.12 \\
\hline $\mathrm{HDL}-\mathrm{C}(\mathrm{mmol} / \mathrm{L})$ & 1760 & 1.25 & (1.17 to 1.32$)$ & 1.27 & (1.24 to 1.30$)$ & 1.27 & (1.25 to 1.30$)$ & 1.30 & (1.27 to 1.32$)$ & 0.07 \\
\hline Glucose (mmol/L) & 1760 & 5.22 & (5.12 to 5.32 ) & 5.17 & (5.13 to 5.20$)$ & 5.21 & (5.17 to 5.24 ) & 5.21 & (5.18 to 5.24 ) & 0.15 \\
\hline Insulin (IU/L)† & 1757 & 9.18 & (8.13 to 10.35 ) & 8.77 & (8.40 to 9.17 ) & 8.94 & (8.58 to 9.31 ) & 8.81 & (8.49 to 9.14 ) & 0.83 \\
\hline $\operatorname{CRP}(\mathrm{mg} / \mathrm{L}) \dagger$ & 1760 & 0.64 & (0.49 to 0.84$)$ & 0.52 & (0.47 to 0.57$)$ & 0.52 & (0.48 to 0.57 ) & 0.44 & (0.41 to 0.48 ) & 0.001 \\
\hline
\end{tabular}

*MET, metabolic equivalent.

tGeometric means.

25(OH)D, Total 25-hydroxyvitamin D; ALSPAC, Avon Longitudinal Study of Parents and Children; Apo-A1, apolipoprotein-A1; Apo-B, apolipoprotein-B; BMI, body mass index; CRP, C reactive protein; DBP, diastolic blood pressure; HDL-C, high density lipoprotein cholesterol; IL6, interleukin 6; LDL-C, low density lipoprotein cholesterol; SBP, systolic blood pressure. 


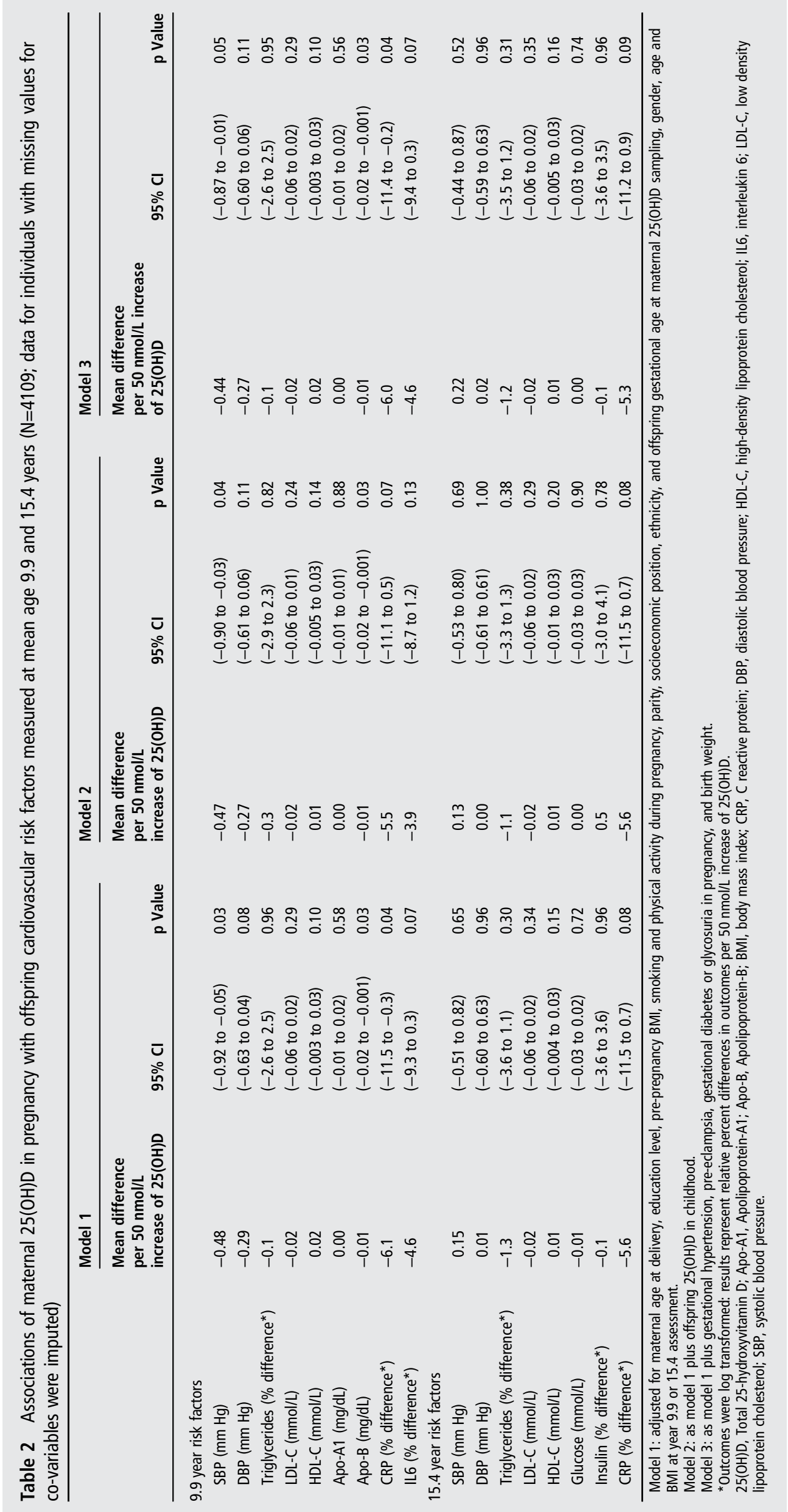




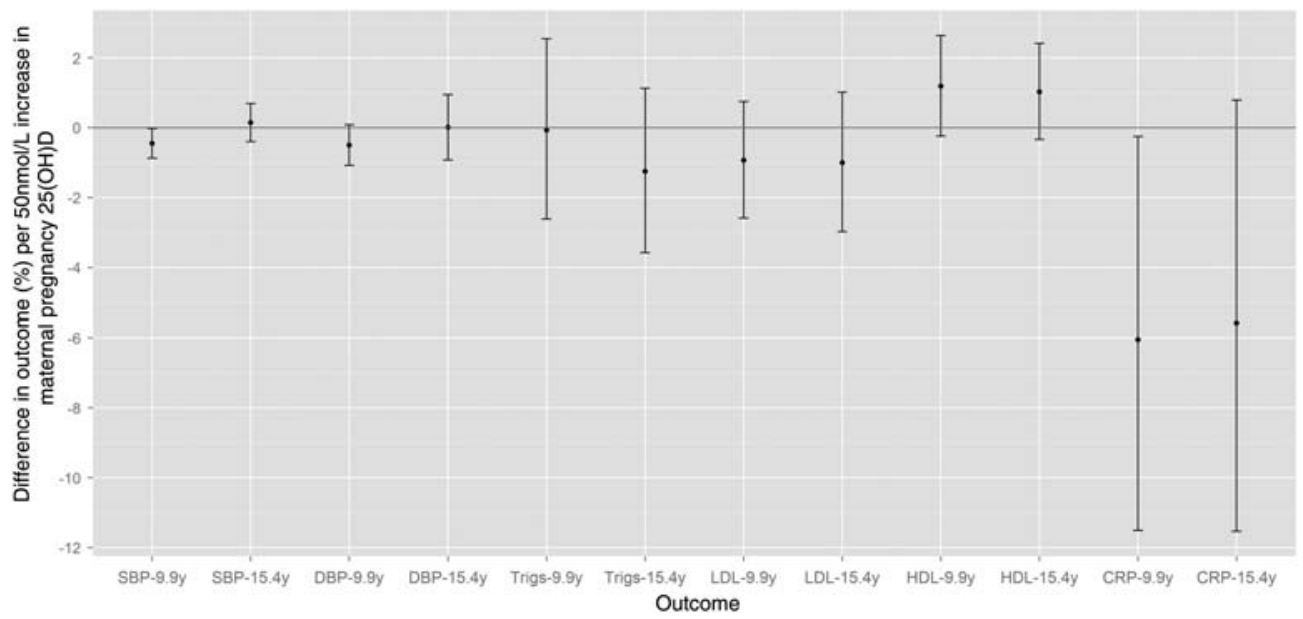

Figure 2 Relative percentage differences (and 95\% Cl) in offspring outcomes at mean age 9.9 and 15.4 years, per $50 \mathrm{nmol} / \mathrm{L}$ of maternal 25-hydroxyvitamin $\mathrm{D}(25(\mathrm{OH}) \mathrm{D})$ in pregnancy $(\mathrm{N}=4109)$. Associations are adjusted for maternal age at delivery, education level, pre-pregnancy body mass index (BMI), smoking and physical activity during pregnancy, parity, socioeconomic position, ethnicity, and offspring gestational age at maternal 25(OH)D sampling, gender, age and BMI at year 9.9 or 15.4 assessment. CRP, C reactive protein; DBP, diastolic blood pressure; HDL, high density lipoprotein; LDL, low density lipoprotein; SBP, systolic blood pressure; Trigs, triglycerides.

to those with maternal $25(\mathrm{OH}) \mathrm{D}>75 \mathrm{nmol} / \mathrm{L}$. This difference was small but followed a dose-response pattern. HDL-C was also lower, and CRP higher, at 15.4 years in those in lower maternal 25 $(\mathrm{OH}) \mathrm{D}$ categories compared to those with maternal $25(\mathrm{OH})$ $\mathrm{D}>75 \mathrm{nmol} / \mathrm{L}$. Further adjustments for potential mediators produced similar results to model 1 for all risk factor associations (model 2 data shown in online supplemental table S5; model 3 data available on request).

There was no evidence that any association deviated from linearity (all fractional polynomial $\mathrm{p} \geq 0.15$ ). There was also limited evidence of interactions between trimester of pregnancy in which $25(\mathrm{OH}) \mathrm{D}$ was sampled and associations of season-adjusted maternal $25(\mathrm{OH}) \mathrm{D}$ with offspring cardiovascular risk factors. The exception was the association with LDL-C at age 9.9 years ( $p$ for interaction $=0.02$; all other $p \geq 0.24$ ). There was an inverse association of LDL-C with maternal $25(\mathrm{OH}) \mathrm{D}$ sampled in trimester 1 , but not with $25(\mathrm{OH}) \mathrm{D}$ sampled in trimesters 2 or 3 .

In general, the directions and magnitudes of associations of maternal $25(\mathrm{OH}) \mathrm{D}$ unadjusted for season of sampling with cardiovascular risk factors were very similar to results of main analyses (see online supplemental table S6). The results of analyses conducted on complete case subsamples are shown in online supplemental table S7. Results were similar to those of analyses conducted on imputed datasets; the main notable difference was an absence of an inverse association of maternal $25(\mathrm{OH}) \mathrm{D}$ with SBP measured at 9.9 years, and the presence of an inverse association with LDL-C at 15.4 years.

Removing participants with high CRP values $(>6 \mathrm{mg} / \mathrm{L}) \mathrm{did}$ not appreciably change associations for inflammatory markers, although the inverse association of maternal $25(\mathrm{OH}) \mathrm{D}$ with CRP at 15.4 years strengthened. In the confounder-adjusted model, there was a $-6.2 \%$ difference in CRP per $50 \mathrm{nmol} / \mathrm{L}$ increase in season-adjusted maternal 25(OH)D (95\% CI -11.6 to -0.4$)$.

Analyses using non-HDL-C and HOMA-IR as outcomes were consistent with those using LDL-C and fasting insulin, respectively (data available on request).

\section{DISCUSSION}

This study provides limited evidence to support the hypothesis that intrauterine $25(\mathrm{OH}) \mathrm{D}$ exposure influences cardiovascular risk factors measured in childhood and adolescence. We found inverse associations between maternal $25(\mathrm{OH}) \mathrm{D}$ measured in pregnancy and offspring CRP measured in childhood and adolescence. We also found evidence for inverse associations of maternal 25(OH)D with offspring SBP and Apo-B at 9.9 years, although there was no association with SBP measured at 15.4 years (Apo-B measurements at 15.4 years were not available). There was no consistent evidence for associations with the following cardiovascular risk factors measured at either assessment: DBP, lipids, IL6, and fasting glucose and insulin (the latter two risk factors measured only in adolescence).

Two small existing studies have examined maternal $25(\mathrm{OH}) \mathrm{D}$ concentrations in pregnancy in relation to offspring cardiovascular risk factors in childhood. ${ }^{8}{ }^{19}$ In the current study, there was some evidence for an inverse association of maternal $25(\mathrm{OH}) \mathrm{D}$ with offspring SBP in childhood, which contrasts with the two previous studies of this nature. However, our results also suggest that associations with blood pressure are not present after childhood. The lack of consistent associations with offspring blood pressure at both of the age points counters the hypothesis that exposure to maternal $25(\mathrm{OH}) \mathrm{D}$ in pregnancy helps to programme lifelong blood pressure in offspring. Fasting insulin at 9.5 years was higher in Indian offspring of mothers with $25(\mathrm{OH}) \mathrm{D}<50 \mathrm{nmol} / \mathrm{L}$ in pregnancy than those whose mothers had $25(\mathrm{OH}) \mathrm{D}$ over $50 \mathrm{nmol} / \mathrm{L}(\mathrm{N}=578),{ }^{8}$ but we found no similar relation of maternal $25(\mathrm{OH}) \mathrm{D}$ to fasting insulin of offspring at 15.4 years. Although we cannot rule out potential ethnic differences in associations, the findings of this study suggest that the effects of in utero $25(\mathrm{OH}) \mathrm{D}$ on fetal pancreatic development, $\beta$-cell function or mechanisms for glucose homeostasis are limited, and maternal $25(\mathrm{OH}) \mathrm{D}$ in pregnancy is unlikely to be a key aetiological risk factor for the future development of type-2 diabetes in offspring.

In the Indian Mysore Parthenon cohort, higher maternal $25(\mathrm{OH}) \mathrm{D}$ status in pregnancy was associated with lower HDL-C in males at 9.5 years (but not females). ${ }^{8}$ In our study, higher maternal $25(\mathrm{OH}) \mathrm{D}$ in pregnancy was only associated with cardioprotective levels of Apo-B, and not Apo-A1 or lipoproteins.

Neither of the previous studies had examined associations of maternal $25(\mathrm{OH}) \mathrm{D}$ with offspring inflammatory markers, and to our knowledge this is the first study to report inverse associations of maternal $25(\mathrm{OH}) \mathrm{D}$ in pregnancy with CRP values in 
offspring. Although standard errors for associations were large (and some confidence intervals included the null), the point estimates for these associations were strong, with CRP values in adolescence decreasing by approximately $5.6 \%$ per $50 \mathrm{nmol} / \mathrm{L}$ of $25(\mathrm{OH}) \mathrm{D}$ in pregnancy.

If such associations are causal and not a result of residual confounding, it is unclear how fetal exposure to $25(\mathrm{OH}) \mathrm{D}$ may affect chronic inflammation (via supply of the active molecule $\left.1,25(\mathrm{OH})_{2} \mathrm{D}\right)$. The vitamin $\mathrm{D}$ system may help to increase the expression of $\mathrm{T}$ helper type 2 (Th2) cells and inhibit $\mathrm{T}$ helper type 1 (Th1) cell differentiation during pregnancy. ${ }^{26}$ Over-expression of Th1 relative to Th2 (along with changes to circulating cytokines produced by these cells) is thought to increase the risk of conditions associated with adverse immunomodulation, such as pre-eclampsia. ${ }^{27}$ It is possible that the determination of the $\mathrm{T}$ cell balance in pregnancy may also programme long term immune responses in offspring. In line with this hypothesis, higher maternal vitamin $\mathrm{D}$ intake or neonatal $25(\mathrm{OH}) \mathrm{D}$ status has been associated with reduced risk of childhood wheezing (which may depend on improved inflammatory response) in offspring. ${ }^{728}$ However, further studies are necessary to increase our understanding of mechanisms linking in utero $25(\mathrm{OH}) \mathrm{D}$ exposure to lifelong inflammatory response.

\section{Strengths and limitations}

Our study has important strengths. It is several times larger than the two existing studies of a similar nature, so we have greater power to detect small but real associations. It is the first to have compared associations of maternal $25(\mathrm{OH}) \mathrm{D}$ with offspring cardiovascular risk factors measured at time points in both childhood and adolescence. We were also able to examine whether associations were due to shared familial characteristics that may influence $25(\mathrm{OH}) \mathrm{D}$ concentrations of both mothers and offspring, rather than being due to intrauterine effects of maternal $25(\mathrm{OH}) \mathrm{D}$ alone. Finally, our analyses were conducted on a large, non-select general population.

The main limitation of the study is attrition to participation across the course of the study, which is common in longitudinal cohorts. However, although there was statistical evidence for differences in several characteristics between the eligible sample and those excluded because of missing data on maternal $25(\mathrm{OH}) \mathrm{D}$ and/or offspring cardiovascular risk factors, these differences were small in magnitude. Furthermore, attrition would only introduce bias if the relationship between maternal $25(\mathrm{OH}) \mathrm{D}$ in pregnancy and offspring cardiovascular risk factors was different in those who originally enrolled but had been subsequently excluded, compared to our included sample, which we do not anticipate. Maternal 25(OH)D was assessed using single measures, so regression dilution may have occurred, and reported results could be weaker than true associations. However, 25(OH)D concentrations have been shown to correlate strongly over time, so a single measure of $25(\mathrm{OH}) \mathrm{D}$ may serve as an acceptable proxy for overall vitamin $\mathrm{D}$ status during the period of exposure measurement (and similarly for childhood vitamin D status). ${ }^{29} 30$

\section{CONCLUSIONS}

The concept of increasing maternal $25(\mathrm{OH}) \mathrm{D}$ concentration during pregnancy in order to improve non-skeletal health outcomes in offspring is novel, and calls from health practitioners advocating vitamin D supplementation in pregnancy for this purpose may be premature. Although our results suggest the possibility of associations of higher $25(\mathrm{OH}) \mathrm{D}$ with healthier concentrations of CRP (and also Apo-B), further prospective studies are required to confirm the findings and experimental studies are required to increase our understanding of potential mechanisms. If findings are replicated elsewhere, randomised controlled trials aimed at increasing maternal $25(\mathrm{OH}) \mathrm{D}$ concentrations in pregnancy would be warranted to see if vitamin $\mathrm{D}$ supplementation can improve levels of chronic inflammation in offspring.

Correction notice The license of this article has also changed since publication to CC BY 4.0.

Acknowledgements We are extremely grateful to all the families who took part in this study, the midwives for their help in recruiting them, and the whole ALSPAC team, which includes interviewers, computer and laboratory technicians, clerical workers, research scientists, volunteers, managers, receptionists and nurses.

Contributions DMW, AF and DAL designed the analysis plan. DMW conducted the analysis with guidance from AF and DAL. WDF, GDS and NS were responsible for data collection of variables related to this analysis. All authors contributed intellectually to the drafting of the manuscript.

Funding This work was supported by a UK Medical Research Council (MRC) Grant (G0701603). The UK MRC and the University of Bristol provide core funding for the MRC Centre of Causal Analyses in Translational Epidemiology (G0600705). AF is funded by a UK Medical Research Council research fellowship. DMW was funded by a Wellcome Trust studentship (WT083431MA)

Competing interests The views expressed in this paper are those of the authors and not necessarily those of any funding body or others whose support is acknowledged. The funders had no role in study design, data collection and analysis, decision to publish, or preparation of the manuscript.

Patient consent Obtained.

Ethics approval ALSPAC Law and Ethics Committee.

Provenance and peer review Not commissioned; externally peer reviewed.

Open Access This is an Open Access article distributed in accordance with the terms of the Creative Commons Attribution (CC BY 4.0) license, which permits others to distribute, remix, adapt and build upon this work, for commercial use, provided the original work is properly cited. See: http://creativecommons.org/ licenses/by/4.0/

\section{REFERENCES}

1 Bodnar LM, Simhan HN, Powers RW, et al. High prevalence of vitamin D insufficiency in black and white pregnant women residing in the northern United States and their neonates. J Nutr 2007;137:447-52

2 Holick MF. Vitamin D deficiency. N Engl J Med 2007;357:266-81.

3 Kovacs CS. Vitamin D in pregnancy and lactation: maternal, fetal, and neonatal outcomes from human and animal studies. Am J Clin Nutr 2008:88:520S-8S

4 Javaid MK, Crozier SR, Harvey NC, et al. Maternal vitamin D status during pregnancy and childhood bone mass at age 9 years: a longitudinal study. Lancet 2006:367:36-43

5 Mahon P, Harvey N, Crozier S, et al. Low maternal vitamin D status and fetal bone development: cohort study. J Bone Miner Res 2010;25:14-19.

6 Fronczak CM, Baron AE, Chase HP, et al. In utero dietary exposures and risk of islet autoimmunity in children. Diabetes Care 2003:26:3237-42.

7 Camargo CA, Rifas-Shiman SL, Litonjua AA, et al. Maternal intake of vitamin D during pregnancy and risk of recurrent wheeze in children at 3 y of age. Am J Clin Nutr 2007;85:788-95

8 Krishnaveni GV, Veena SR, Winder NR, et al. Maternal vitamin D status during pregnancy and body composition and cardiovascular risk markers in Indian children: the Mysore Parthenon Study. Am J Clin Nutr 2011;93:628-35.

9 Bodnar LM, Catov JM, Simhan HN, et al. Maternal vitamin D deficiency increases the risk of preeclampsia. J Clin Endocrinol Metab 2007;92:3517-22.

10 Bodnar LM, Catov JM, Zmuda JM, et al. Maternal serum 25-hydroxyvitamin D concentrations are associated with small-for-gestational age births in white women. J Nutr 2010;140:999-1006.

11 Leffelaar ER, Vrijkotte TG, van Eijsden M. Maternal early pregnancy vitamin D status in relation to fetal and neonatal growth: results of the multi-ethnic Amsterdam Born Children and their Development cohort. Br J Nutr 2010;104:108-17.

12 Powe $C E$, Seely EW, Rana $S$, et al. First trimester vitamin $D$, vitamin $D$ binding protein, and subsequent preeclampsia. Hypertension 2010;56:758-63.

13 Morley R, Carlin JB, Pasco JA, et al. Maternal 25-hydroxyvitamin D and parathyroid hormone concentrations and offspring birth size. J Clin Endocrinol Metab 2006;91:906-12.

14 Geelhoed JJM, Fraser A, Tilling K, et al. Preeclampsia and gestational hypertension are associated with childhood blood pressure independently of family adiposity measures/clinical perspective. Circulation 2010;122:1192-9. 
15 Lawlor DA, Hubinette A, Tynelius P, et al. Associations of gestational age and intrauterine growth with systolic blood pressure in a family-based study of 386485 men in 331089 families. Circulation 2007:115:562-8.

16 Huxley R, Owen CG, Whincup PH, et al. Is birth weight a risk factor for ischemic heart disease in later life? Am J Clin Nutr 2007:85:1244-50

17 Fraser A, Williams D, Lawlor DA. Associations of serum 25-hydroxyvitamin D, parathyroid hormone and calcium with cardiovascular risk factors: analysis of 3 NHANES cycles (2001-2006). PLOS ONE 2010;5:e13882.

18 Williams D, Fraser A, Sayers A, et al. Associations of 25-hydroxyvitamin D2 and D3 with cardiovascular risk factors in childhood: cross-sectional findings from the Avon Longitudinal Study of Parents and Children. I Clin Endocrinol Metab 2012;97:1563-71.

19 Gale CR, Robinson SM, Harvey NC, et al. Maternal vitamin D status during pregnancy and child outcomes. Eur J Clin Nutr 2008:62:68-77.

20 Fraser A, Macdonald-Wallis C, Tilling K, et al. Cohort Profile: The Avon Longitudinal Study of Parents and Children: ALSPAC mothers cohort. International Journal of Epidemiology 2012; doi:10.1093/ije/dys066

21 Boyd A, Golding J, Macleod J, et al. Cohort Profile: The 'Children of the 90s'; the index offspring of The Avon Longitudinal Study of Parents and Children (ALSPAC). International Journal of Epidemiology 2012; doi:10.1093/ije/dys064
22 Royston P, Ambler G, Sauerbrei W. The use of fractional polynomials to model continuous risk variables in epidemiology. Int J Epidemiol 1999;28:964-74.

23 Royston P. Multiple imputation of missing values. Stata J 2004:4:227-41.

24 Boekholdt SM, Arsenault BJ, Mora S, et al. Association of LDL cholesterol, non-HDL cholesterol, and apolipoprotein B levels with risk of cardiovascular events among patients treated with statins. JAMA 2012;307:1302-9.

25 Matthews D, Hosker J, Rudenski A, et al. Homeostasis model assessment: insulin resistance and $\beta$ cell function from fasting plasma glucose and insulin concentrations in man. Diabetologia 1985;28:412-19.

26 Spilianakis $C$, Lee G, Flavell R. Twisting the Th1/Th2 immune response via the retinoid $X$ receptor: lessons from a genetic approach. Eur J Immunol 2005;35:3400-4.

27 Saito S, Sakai M. Th1/Th2 balance in preeclampsia. J Reprod Immunol 2003;59:161-73.

28 Camargo CA, Ingham T, Wickens K, et al. Cord-blood 25-hydroxyvitamin D levels and risk of respiratory infection, wheezing, and asthma. Pediatrics 2011;127:e180-7.

29 Hofmann JN, Yu K, Horst RL, et al. Long-term variation in serum 25-hydroxyvitamin D concentration among participants in the prostate, lung, colorectal, and ovarian cancer screening trial. Cancer Epidemiol Biomarkers 2010;19:927-31.

30 Major JM, Graubard BI, Dodd KW, et al. Variability and reproducibility of circulating vitamin D in a nationwide US Population. J Clin Endocrinol Metab 2013;98:97-104. 


\section{Corrections}

Williams DM, Fraser A, Fraser WD, et al. Associations of maternal 25-hydroxyvitamin $\mathrm{D}$ in pregnancy with offspring cardiovascular risk factors in childhood and adolescence: findings from the Avon Longitudinal Study of Parents and Children. Heart 2013;99:1849-56. This article should have been published under a CC-BY license and not a CC-BY-NC license.

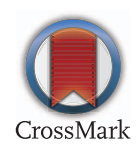

Heart 2015;101:162

doi:10.1136/heartjnl-2013-303678corr1 